DOI: https://doi.org/10.35699/2238-037X.2019.9572

\title{
O MÚSICO E SEU TRABALHO NA NOVA ORDEM MUSICAL DA CIDADE DE BELO HORIZONTE ${ }^{1}$
}

\author{
The musician and his work in the new musical order of Belo Horizonte city
}

ALVES, Valmir Alcantara²

MARTINS, Maria de Fátima Almeida ${ }^{3}$

\begin{abstract}
Resumo
O artigo é fruto da tese de doutorado "A relação do músico com o trabalho: quando o trabalho do músico passa de trabalho improdutível para produtível em Belo Horizonte", defendida em 2018 na Faculdade de Educação da UFMG, tem como objeto de análise o músico e seu trabalho na cidade Belo Horizonte. O objetivo é apresentar discussões que foram tratadas na pesquisa sobre os atuais processos de mercantilização do trabalho do músico na cidade, tendo como ponto de partida as análises sobre as relações do músico e seu trabalho, compreendidas como uma atividade humana específica em produzir som, por exemplo, e, como esta é incorporada no circuito mercantil na cidade de Belo Horizonte. O que se constatou foi que o cenário de exploração da força de trabalho do músico no capitalismo metamorfoseia-se, criando novas nomenclaturas como espécie de "maquiagem" da exploração do trabalhador da música. A reprodução capitalista nesse setor pode ser observada sob diversas faces, como, por exemplo, as leis de incentivo à cultura, pensadas como forma de garantir a reprodução dos capitais envolvidos nessa atividade, transformando-a em um modelo econômico da produção artística no Brasil. O texto tem o sentido de elucidar o que vem a ser o trabalho do músico, que é bastante diverso e múltiplo na cidade de Belo Horizonte, uma vez ser esta uma "cidade musical", pois, antes mesmo da sua fundação, já existiam músicos que estabeleciam seus trabalhos na cidade MARTINS, 2006). Na história da música na cidade, na última década do século passado, os movimentos sociais e artísticos estabeleceram uma nova ordem musical, e o melhor exemplo foi o renascimento do carnaval de rua que revela a atuação desse músico na nova ordem musical da cidade e no circuito mercantil enquanto trabalhador.
\end{abstract}

Palavras-chave: Trabalho. Músico. Circuito Mercantil. Ordem Musical. Belo Horizonte.

\section{ABstract}

This article, is a result of the doctoral thesis "The relation of the musician to the work: when the musician's work changes from unproductive work to productive in Belo Horizonte", defended in 2018 at the Faculty of Education of UFMG, has the object of analysis musician and his work in the city Belo Horizonte. The objective is to present discussions that were dealt with in the research on the current processes of commercialization of the work of the musician in the city, starting from the analyzes about the relations of the musician and his work initially understood as a specific human activity in producing sound, for example, and, secondly, how it is incorporated in the mercantile circuit in the city of Belo Horizonte. In the thesis, what was verified was that the scenario of exploitation of the musician's workforce in capitalism metamorphoses itself, creating new nomenclatures as kind of "makeup" of the exploitation of the music worker. The capitalist reproduction in this sector can be observed under various facets, such as, for example, laws to encourage culture, designed as a way of guaranteeing the reproduction of the capital involved in this activity, transforming it into an economic model of artistic production in Brazil. The text

\footnotetext{
${ }^{1} \mathrm{O}$ artigo é resultado da pesquisa de doutoramento sobre: A relação do músico com o trabalho: quando o trabalho do músico passa de trabalho improdutível para produtível em Belo Horizonte defendida em 2018 no Programa de Pós Graduação em Educação: Conhecimento e Inclusão da Faculdade de Educação da UFMG. A mesma foi submetida ao comitê de Ética, COEP, tendo sido contemplada com bolsa de doutorado da Capes.

${ }^{2}$ Doutor em Educação pela Universidade Federal de Minas Gerais. Formado em História pelo Centro Universitário de Belo Horizonte. Email: valmirarteeducacao@gmail.com

${ }^{3}$ Professora Associada da Faculdade de Educação. Formada em Geografia pela Universidade Federal do Ceará, coordenadora do Curso de Licenciatura em Educação do Campo. E-mail: falmartins.ufmg@gmail.com
}

Trabalho \& Educação | v.28 | n.2 | p.113-130 | maio-ago | 2019 
also has the sense of elucidating what the work of the musician is, which is quite diverse and multiple in the city of Belo Horizonte, once this is a "musical city", since even before its founding there were already musicians (Martins, 2006). In the history of music in the city, in the last decade of the last century, social and artistic movements established a new musical order, and the best example was the rebirth of the street carnival that reveals the performance of this musician in the new musical order of the city and in the commercial circuit as a worker.

Keywords: Work. Musician. Mercantile Circuit. Musical Order. Belo Horizonte.

\section{INTRODUÇÃO}

Como trabalhador da música, refletir na academia sobre o trabalho do músico foi a forma encontrada para falar sobre a prática no diálogo com o outro, produzindo e refletindo sobre o trabalho do músico. Assim, a tese "A relação do musico com o trabalho: a produtividade do trabalho do musico em belo horizonte" (ALVES, 2017) foi tomada como um direito de falar "de dentro para fora", de uma pesquisa que nasce da experiência do músico e pesquisador; assim acreditamos na quebra de paradigmas sobre dar voz ao trabalhador da música. O olhar e a vivência do músico pesquisador trazem um extrato de conhecimento que não é tradicional na academia.

Fazendo uma análise histórica do trabalho nas várias categorias de trabalhador, logo verificamos que falta representatividade do músico, seja no âmbito do sindicato ou em leis trabalhistas. Embora a ancestralidade do músico e seu trabalho remontem a antes de Cristo, sua legalidade sempre foi constituída por percalços. Esses percalços começam pela dupla imagem, que será explorada ao longo deste texto, na qual o público, na sua maioria, encara o músico como uma pessoa que se diverte ao executar seu labor ou, em outros momentos, o associa à boemia e à diversão regada a drogas lícitas e ilícitas.

Os músicos e seu trabalho aqui pesquisados produzem a música popular vinda dos novos fenômenos sociais das últimas décadas na cidade de Belo Horizonte, ou seja, o artista coletivo. Ao resgatar as imagens sobre o músico e seu trabalho, observamos que alguns avanços ocorreram na representação da imagem construída sobre o profissional que executa a música, porém esses avanços geralmente fazem referência aos músicos de orquestras e os consagrados no mercado fonográfico. Seguindo o pensamento de Elias:

Nas reflexões sociológicas sobre a vida do músico Wolfgang Amadeus Mozart (1756-1791), Nobert Elias buscou compreender a experiência social do artista burguês na corte aristocrática. $\mathrm{Na}$ verdade, Elias acabou por fazer uma sociologia da singularidade, transpondo para a escala de uma biografia o problema maior das restrições às quais se submetem os indivíduos no processo de civilização (LEÃO, 2007, p. 53).

A experiência social tratada pela autora acima abre um leque de hipóteses que, acreditamos, está associada aos tempos de hoje, partindo da reflexão de que no Brasil a educação escolar e musical tem a cultura europeia sua referência.

Sobre o que venha a ser o trabalho do músico na cidade de Belo Horizonte, percebemos que a face encoberta ao longo de toda história nos possibilitou construir um estudo que ainda podemos chamar de inédito no campo cientifico no mundo do trabalho.O trabalho

\footnotetext{
${ }^{4}$ Tese de doutorado "A relação do músico com o trabalho: quando o trabalho do músico passa de trabalho improdutível para produtível em Belo Horizonte", foi defendida em 2018 por Valmir Alcântara Alves e orientada pela professora doutora Maria de Fátima Almeida Martins.
} 
do músico neste artigo transita no oposto dessa confluência cultural que, emblematicamente chamaremos de artista não cortesão autônomo: aquele que, conduzido por sua arte, busca romper com estratificações sociais. É este que enfrenta a sua desvalorização, a precarização histórica do seu trabalho e tem que provar, a cada momento em que executa sua obra, que é capaz de sustentar o que se dispôs a fazer como parte principal da sua vida: a música.

\section{A MÚSICA COMO TRABALHO NA CAPITAL BELO HORIZONTINA}

Ao optarmos por destacar o trabalho do músico na cidade de Belo Horizonte, fomos ao cerne de uma necessidade explícita na categoria dos músicos. Foram cerca de cinco anos de laboratório sobre a viabilidade da pesquisa, ou seja, antes mesmo de se iniciar, efetivamente, o doutorado, já se realizavam diálogos com diversos profissionais da música, os quais foram sistematizados na tese. Durante esses anos, foi possível concluir que há uma inexistência de apontamentos concretos sobre o significado do que é o trabalho do músico, ou o que venha a ser esse trabalho, suas necessidades, suas conquistas.

A capital do estado de Minas Gerais sempre foi um celeiro de grandes músicos para o Brasil. A cena musical belo-horizontina sempre foi efervescente, segundo um dos músicos entrevistados para a pesquisa, o maestro Marilton Borges, integrante do movimento musical do Clube da Esquina. Ele nos reporta à Belo Horizonte da década de 1960 e cita os edifícios Levy e Maleta, no centro da cidade, como ponto de encontro de músicos como Milton Nascimento e Toninho Horta, além de seus irmãos Lô Borges e Marcio Borges que recebiam convites para participarem de festivais no Rio de Janeiro e São Paulo.

Toda essa música popular brasileira, juntamente com o Heavy Metal e a música instrumental, destaca Belo Horizonte no cenário musical nacional. Havia também os bailes Black, como o saudoso "Máscaras Negras", no centro da cidade, onde a comunidade negra sempre estava presente ao som do Soul de 1970.Em meados da década de 1980 e início dos anos 90, o Pop Rock e a música eletrônica vão ditar moda musical na cidade. Pato Fu, Skank, Jota Quest e o DJ Anderson Nois e são os destaques, juntamente com o ícone do Heavy Metal Sepultura, considerado o grupo musical brasileiro de maior repercussão no mundo.Também fazem parte desse cenário, as famosas lojas de discos de vinis, como era o caso da Cogumelo, que até hoje promove encontros da cena Rock 'n Roll na capital.

Também temos exemplos consistentes da luta cotidiana dos músicos em prol de melhorias em suas condições de trabalho, como o surgimento da Sociedade Independente da Música (SIM) em 2005, movimento formado por músicos de Belo Horizonte e a fundação, em 2007 da primeira Cooperativa de Trabalho dos Profissionais de Música do Estado de Minas Gerais (Comum) e do Fórum da Música de Minas Gerais. Além da Comum, o Fórum reúne representantes da Sociedade Independente da Música (SIM), da Associação Artística dos Músicos de Minas Gerais (AMMIG), do Museu do Clube da Esquina e do Fora do Eixo Minas (FJP, 2010).

Ainda em 2008, grupos da cultura Hip-Hop, que desde a década de 80 já se encontravam para dançar e cantar, juntaram-se aos jovens da nova geração do Hip Hop e iniciaram um encontro semanal na Praça Sete. Com o passar das semanas, resolveram se deslocar para a Praça da Estação e, num desses encontros, caiu uma chuva de verão. 
A partir daí, buscaram abrigo embaixo do viaduto Santa Teresa, que, por ironia do destino, já contava com palco e pista para skate, até então pouco utilizados. Foi aí que o movimento do Duelo de MC's ganhou força e, nos anos seguintes, virou uma das referências culturais da cidade.

A região da Praça da Estação sempre foi um lugar discriminado da cidade, assim como a zona boêmia da rua Guaicurus, a região da Rodoviária e o bairro Lagoinha. Apesar da criação do Museu de Artes e Ofícios na antiga estação central, com o intuito de "revitalização" do entorno, o viaduto Santa Tereza continuou tendo como frequentadores e moradores a população menos favorecida economicamente, junto à população em situação de rua. O fato é que, com a evolução do Duelo de MC's, houve um início de revalorização da região.

Lojas fechadas há anos abriram-se; abriu-se espaço para bares temáticos, grupos de teatro e, na sequência, após proibição, pela Prefeitura de Belo Horizonte, de realização de eventos na Praça da Estação, surgiu a chamada Praia da Estação, em tom de protesto contra o decreto municipal que impedia manifestações culturais nesse espaço. Os integrantes desses movimentos sociais, em sua maioria, artistas, sujeitos da nossa pesquisa, estão inseridos na luta cotidiana pela melhoria das condições de trabalho do músico e, ao mesmo tempo, vêm promovendo a sua música, que, para eles, não se trata de uma música mineira, mas sim de uma "World Music", como preferem adjetivar suas produções.

$\mathrm{Na}$ referida tese, bem como reforçamos neste texto, optamos por uma metodologia na qual a vivência do pesquisador pudesse contribuir diretamente com a investigação; assim a pesquisa com base na História Oral se fez necessária por ser esta uma pesquisa que busca dar voz ao músico de forma que ele fale de maneira espontânea sobre o que pensa do seu trabalho. Assim, iniciamos a coleta de informações e, depois, fomos à literatura para desafiar as descobertas. O percurso metodológico foi construído numa dinâmica em que cada músico pudesse representar o seu estilo e pertencimento étnico na cidade de Belo Horizonte, pois, diante da diversidade cultural da cidade, foi necessário selecionar artistas que fizeram e fazem parte do nosso recorte temporal de 1998 a 2017 , independentemente de serem belo-horizontinos ou não.

A utilização da metodologia da História Oral possibilitou, ao mesmo tempo, criar e dar sentido ao que buscamos no sujeito da pesquisa: analisar e interpretar o que Pierre Nora cunhou como "lugares de memória" (1993, p. 21); um caminho percorrido na trajetória do artista que diz muito quem ele é. O tempo todo teremos essa "vontade de memória" (NORA, 1993, p. 22). O percurso metodológico seguiu com pré-entrevistas, pesquisas bibliográficas, análise de eventos e trabalhos para conhecimento prévio da memória coletiva dos entrevistados. Na segunda etapa, foi feita uma análise interpretativa das transcrições e da escrita videográfica.

A pesquisa prévia se deu pelas noites e dias na cidade de Belo Horizonte, além de batepapo de camarim, bastidores de saídas de blocos, encontros nas estações de metrôs e ônibus, diálogos via redes sociais e até conversas informais, como em intervalo de jogo no estádio Mineirão, ou seja, em lugares onde havia a disponibilidade do artista para falarmos sobre o tema. Aqui destaco a importância das pesquisas prévias, que nos levam à seguinte questão sobre a pré-entrevista, que a metodologia chama de

"estudo exploratório" é essencial não só porque ela nos ensina a fazer e refazer o futuro roteiro da entrevista. Desse encontro prévio é que se podem extrair questões na linguagem 
usual do depoente, detectando temas promissores. A pré-entrevista abre caminhos insuspeitados para a investigação" (BOSI, 2003, p. 60-61).

A escuta dos que trabalham e vivem da música em Belo Horizonte foi realizada em locais onde o artista estava, seja no camarim ou nas rodas de conversa com os artistas. Esse primeiro movimento foi importante para ouvi-los e, ao mesmo tempo, torná-los potenciais pensadores responsáveis também pela pesquisa desejada. A partir desses encontros é que foi traçado não somente o roteiro para as entrevistas, mas, também, o início das hipóteses sobre qual músico entrevistar e por que seria pontual para a nossa tese. É importante frisar, também, que, durante os encontros prévios, houve um clima de informalidade e algumas questões colocadas foram resgatadas durante as entrevistas diante da câmera, por via do resgate das memórias.

A partir desse conhecimento prévio de cada um dos artistas ${ }^{5}$, foram escolhidos os lugares das entrevistas e bate-papos: tivemos encontros em estabelecimentos culturais, ocupações, estúdios, praças e residências. Alguns lugares, porém, tinham como importância o imaginário do entrevistado; a encruzilhada, por exemplo, sempre foi o lugar da cultura negra, e partimos dela como operadora de linguagens e de discursos, como um lugar terceiro. Afirma Leda Martins, em sua obra "A Oralitura da Memória", que isso é geratriz de produção de significado diversificados e, portanto, de sentidos plurais que:

nessa via de elaboração, as noções de sujeito híbrido, mestiço e liminar, articuladas pela crítica contemporânea, podem ser pensadas como indicativas de alguns dos efeitos de processos e cruzamentos discursivos, intertextuais e interculturais. Nessa concepção de encruzilhada discursiva destaca-se, ainda, a natureza cinética e deslizante dessa instância enunciativa e dos saberes ali instituídos (MARTINS,1997, p. 25-26, Apud, MARTINS, 2006).

Trazer esses significados das linguagens é importante para nos certificar de que estamos falando de "dentro para fora", e que, primeiramente, estamos em um campo metodológico de estudos no qual os conceitos teóricos ainda são recentes: são estudos construídos há décadas e, hoje, encontramos diálogos possíveis na academia para, enquanto músico e pesquisador negro, tomar esses conhecimentos públicos.

A metodologia a partir da História Oral foi necessária para fugir da obviedade e não cair no erro da emoção, com vistas à objetividade da pesquisa ou, como destacou Nobert Elias em "A sociologia de Mozart", ao trabalhar a biografia do compositor, não ceder às facilidades e às seduções daquilo que o sociólogo Pierre Bourdieu chamou de "ilusão biográfica", ou seja, a ilusão que "organiza a trajetória dos indivíduos em posições sucessivamente ocupadas na história de vida" (BOURDIEU,1994, p. 81-89, Apud, BORGES, 2007). A pesquisa, não teve como objetivo construir uma metodologia inovadora, mas métodos que consideramos mais adequados para uma pesquisa muito complexa.

\footnotetext{
${ }^{5}$ Entrevistados:

Marilton Fragoso Borges - entrevista 14.05.2016.

Makely Oliveira Soares Gomes - entrevista dia 07.05.2016

Rodrigo Márcio Cardoso Borges - entrevista dia 14.05.2016.

Tadeu Martins Soares - entrevista dia 20.10.2017.
} 
Acredita-se que são exatamente esses fatores que protegem esse patrimônio imaterial da nossa ancestralidade africana e indígena brasileira: só a decifra quem a vive cotidianamente. Assim, para podermos atingir o conhecimento do que venha ser 0 trabalho do músico na cidade de Belo Horizonte, foi necessário saber também os códigos dos músicos entrevistados, em sua maioria Negros e Negras e Indígenas. Por isso, a noção territorial se fez necessária, até mesmo o poder de improvisação, o que é comum para o músico.

Assim o jazzista retece os ritmos seculares, transcriando-os dialeticamente numa relação dinâmica, retrospectiva e prospectiva. As culturas negras, em seus variados modos de asserção, fundam-se dialogicamente em relação aos arquivos e repertórios das tradições africanas, europeias e indígenas, nos jogos de linguagem, intertextuais e interculturais, que performam (MARTINS, 2006, p. 65).

A memória viva dos entrevistados foi o que conduziu o diálogo e sempre desconfiados, ao perceberem que estávamos querendo deles a sua contribuição para o estudo, aos poucos foram se soltando e, já no fim da entrevista, tivemos o início de uma sintonia nas mensagens, o que proporcionou a fluidez dos encontros. Isso fez com que as últimas palavras viessem com o peso dos seus saberes no intuito mesmo de serem divulgadas. O conceito de escrita videográfica (MAUAD, 2010) nos ajudou a encaminhar metodologicamente a forma das entrevistas, de forma que os entrevistados se sentissem mais à vontade para estabelecer o diálogo.

O formato do mercado musical em Belo Horizonte se difere do restante do país. Existe uma "qualidade" na sua produção musical que já vem de longa data e sobre a qual, segundo os mais variados críticos de música do país, não se consegue chegar a uma concepção. Do circuito musical da cidade, podemos destacar os principais: Conexão BH de música, Festival de Arte Negra-FAN, I Love Jazz, Tudo é Jazz, Festa da Música, Natura Musical, Festival S.E.N.S.A.C.I.O.N.A.L, Aqui Jazz, Cantautores, BH Indie Rock e o Duelo Nacional de MCs, Festival de Hip-Hop, e a retomada do carnaval de Belo Horizonte, desde 2009, onde e quando ocorre o encontro praticamente da maioria dos artistas envolvidos nos festivais citados, transvestidos em seus respectivos blocos e bailes carnavalescos. Esses são os circuitos mercantis da música em Belo Horizonte.

Nosso entendimento e ponto de partida foi o recorte local com um teor universal sobre 0 tema, mediando, na análise, o debate posto pelos estudos marxistas, quando se trata da arte e da indústria cultural. Nessa perspectiva, produzimos um conhecimento que vem contribuir para desvelar esse ambiente antagônico em que se encontra o músico, articulando as características do atual mercado de trabalho musical, cientes de que este ainda se encontre numa encruzilhada dialógica diante da indústria mercadológica da cultura.

O sociólogo francês Pierre Michel Menger, em sua obra "O retrato do artista enquanto trabalhador - metamorfoses do capitalismo", nos revela o confronto do artista versus o capitalismo. Sobre esse enfrentamento, temos diversas análises que nos conduzem ao pensamento de que o mercado econômico, nos seus variados setores, absorveu a filosofia da arte e o comportamento dos artistas no que tange à criatividade e à flexibilidade para atingir seu apogeu. Embora pareça implícito, o trabalho artístico é gerado no modelo como trabalho não alienado, no qual o sujeito se completa com o poder de liberdade em volta da sua criação artística.

$\mathrm{Na}$ tradição de análise sobre o trabalho do artista, especula-se sobre o modelo de trabalho ideal e desejável, o que nos leva a uma dicotomia segundo a qual o homem 
realiza a sua humanidade pela ação e pelo trabalho. Para nos aproximar do que venha a ser o trabalho do músico ou quando essa atividade criativa ganha o conceito de trabalho, Menger discorre que:

\begin{abstract}
a criação artística ocupa com efeito uma posição excepcional nos primeiros escritos de Marx, em particular nos seus Manuscritos de 1844 onde é elaborada não uma estética específica, mas uma estética geral da prática que faz da atividade artística o instrumento de medida de toda a crítica do trabalho assalariado. O agir humano, numa tal concepção, não se pode exprimir plenamente a não ser com a condição de não se transformar em meio para obter outra coisa em particular um ganho (MENGER, 2005, p. 49).
\end{abstract}

Partindo dessas colocações, é necessário entendermos que, uma vez inserida nas relações sociais em que está posto o modelo econômico capitalista, sua arte como produto, no caso o músico e sua música, passa a ser o seu trabalho. O músico, ao executar a sonoridade, expõe uma maneira, uma extensão do seu corpo aliado ao instrumento musical, que pode ser, inclusive, somente seu corpo, o seu poder criativo. É exatamente com essa perspectiva que temos avançado no campo de estudos sobre o trabalho do músico, sabendo que, quando falamos de trabalho produtível, falamos de trabalho socialmente determinado, força de trabalho, o trabalho no processo de produção capitalista (MARX; ENGELS, 1986).

O processo de criatividade não condiz com a cronologia cotidiana e está para além do valor mercadológico, mesmo quando recorremos aos estudos da indústria cultural, pois é possível entender que o conceito de indústria cultural construído por Horkheimer e Adorno em 1947 veio para substituir a expressão "cultura de massa". Esse conceito nos leva a entender como o comportamento que vem das próprias massas foi constante objeto de crítica feita por Adorno. Trata-se do fato de padronizar as manifestações culturais em prol da massificação da cultura e, por consequência, gerar apenas um produto econômico a serviço do chamado fetichismo da arte. Fato que não poderia contribuir para o significado da Arte enquanto elemento crítico de uma sociedade (HORKHEIMER; ADORNO, 1985, p. 114).

A conexão que fazemos aqui sobre o trabalho do músico na cidade de Belo Horizonte e em relação com o mundo, dialoga com a antologia da chamada Escola de Frankfurt, nascida em 1924, que se tornou referência de estudo quando se trata da arte e sua indústria. Um exemplo a ser observado é a crítica que Adorno dirige ao que aqui aparece sob o nome de "música popular". Ele afirma que a música popular

não diz respeito a uma possível incompetência de seus compositores e arranjadores, mas, pelo contrário, ao fato de sua grande perícia ser totalmente neutralizada e reorientada em função das exigências dos monopólios culturais no sentido da padronização com o objetivo de garantir o retorno financeiro e a aprovação tácita ao status quo. O conceito de "pseudoindividualização" aponta exatamente para esse reforço ideológico que a música de massa proporciona para a manutenção do existente (ADORNO, 1986, p.35).

A partir do advento capitalista pós-segunda guerra mundial, a "cultura" passou a ser regida pelas leis da mercadoria. Assim, o termo "indústria cultural" conceitua um fenômeno em que ocorre a total mercantilização da produção simbólica dos indivíduos e, com isso, a anulação da sua humanidade. Importante salientarmos que a indústria cultural não se resume à produção de necessidades iguais, de comportamentos padronizados, de obstrução à consciência e veto à crítica. Ela parte da ação de entreter fabricando diversão, exercendo domínio e mediando quem consome seu produto, tornando um império do capitalismo o que é basicamente uma extensão do trabalho. 
Uma vez que, ao findar o dia, o retorno do trabalhador para sua residência não pode se tornar algo desprezível e ruim, entra em cena o fantástico mundo da alienação com os produtos que irão renovar este trabalhador a fim de que esteja pronto novamente para o dia seguinte de trabalho. A televisão, com suas novelas, missas, cultos, filmes (que às vezes também são simultâneos no rádio e redes sociais), juntamente com a música, são alguns dos itens que não podem faltar no pacote que fará o indivíduo mais "feliz" para a nova jornada.

Diante deste cenário concreto, o trabalhador músico se encontra como algoz do próprio destino, qual seja, o de viver da arte que o aliena, produzir sua alegria e dor, melancolia em certos momentos, o que pode render uma poesia profunda e, mais à frente, consagrá-lo como um artista além do seu tempo. O exercício da criatividade que é estimulado nos indivíduos, pela poesia, pela imaginação, baseado na coletividade artística, pode trazer consigo uma compreensão da subjetividade dos versos à objetividade concreta da vida do próprio músico, pois

[a] vida é por essência um processo prático-sensível. Ele entra obrigatoriamente em contatos práticos com objetos que resistem ao homem, que o criam, modificam-no e enriquecem-no. No curso da atividade exterior, o círculo dos processos psíquicos se abre de algum modo ao mundo material objetivo, que aí promove imperiosa erupção. Tem a função particular de situar o sujeito na realidade objetiva e de subjetivá-la. (CUNHA apud ARANHA; CUNHA; LAUDARES, 2005 p. 122).

Nessa perspectiva, a dubiedade da vida do sujeito enquanto artista e produtor de uma força de trabalho pode se estabelecer a partir da compreensão deste sobre o contexto social em que está inserido. O trabalho do artista, ao produzir sonoridades, o leva a um lugar de protagonismo e, em certo momento de autonomia do sujeito, de poder alcançar, com sua subjetividade, uma ideologia e, de certo modo, uma filosofia de vida que pode ser referência naquilo a que o músico se propõe. O que ele está fazendo é o seu trabalho, que, embora pareça ou se confunda com o seu próprio lazer, é seu trabalho e é também, por que não, seu mundo, o universo criativo que o leva "a motivos das vantagens não monetárias e tão poderoso que tem fornecido a base do encantamento ideológico do trabalho artístico" (MENGER, 2005, p. 92).

Importantes essas colocações para que saibamos que estamos lidando com o mundo do trabalho em que, independente da época de florescimento do capital, existe uma busca incansável do artista em confrontar sua obra de arte com as demais necessidades sociais, ao ponto de uma ser tão importante quanto a outra, e que o sentido pode não acompanhar as circunstâncias baseadas somente no capital. As posturas dos artistas podem ser de rompimento dos padrões exigidos, sejam eles estéticos ou financeiros.

Essas situações funcionam mais como uma brecha para o artista se manifestar do que um encaixe na situação colocada dentro da sociedade em que o consumo é exacerbado. A atividade criativa a priori anuncia um rompimento com o que está posto, é um instrumento de crítica social que nos leva a remontar o que pode ser mais dinâmico para o meio em que vivemos, dialogando com a nossa essência, com o nosso poder de criar, seja individualmente, seja coletivamente. É importante que tomemos para nós mesmos a responsabilidade de sermos coletivos e, portanto, reconheçamos a potencialidade do homem coletivo, o qual é colocado por Paulo Freire:

O homem enche de cultura os espaços geográficos e históricos. Cultura é tudo o que é criado pelo homem. Tanto uma poesia como uma frase de saudação. A cultura consiste em 
recriar e não repetir. O homem pode fazê-lo porque tem uma consciência capaz de captar o mundo e transformá-lo (FREIRE, 2007, p. 30).

Através dessa afirmação de Freire, acreditamos que estamos construindo um conhecimento que venha a contemplar uma nova realidade para a compreensão de quem produz arte, em especial o músico, evidenciando a coletividade como um forte aliado para a inserção nas diversas modalidades mercadológicas no advento do capitalismo do século XXI. Dessa maneira, associações e cooperativas constituem novas formas de procura de trabalho vividas tanto por músicos como por empregados formais protegidos socialmente que procuram complementar renda (orquestras, sobretudo). Afinal, a maioria dos músicos autônomos vive de editais em editais, de cachês em cachês, sem proteção social em um mercado cada vez mais concorrido e financiado por leis de incentivo à cultura.

\section{O Músico no CIRCUITO MERCANTIL dA música EM BELo HoRIZONTE}

A virada da década de 1990 para os anos 2000, com relação às políticas públicas no setor da música em Minas Gerais, trouxe muita esperança para o músico. Este, que sempre dependia de convites esporádicos. A partir das leis de incentivo, precisamente nos anos 2000, eclodiram os festivais de música. Um dos maiores deles era o Conexão Telemig Celular de Música, o qual inicialmente, contou com artistas que já vinham de um crescimento de mercado com trabalhos realizados no campo fonográfico e com ampliação de público, como foram os casos de Mauricio Tizumba, Vander Lee, Titane, da banda Berimbrow, Marina Machado, Marku Ribas e outros.

A estratégia desse festival era conciliar o músico em crescimento com outro artista já conhecido no cenário nacional. Assim, um músico em ascensão de Belo Horizonte convidava um mais famoso, como espécie de apadrinhamento. Vander Lee, por exemplo, nas versões iniciais do Conexão Telemig Celular de Música, convidou Luís Melodia, Zeca Baleiro e Elza Soares; a cantora Marina Machado convidou Seu Jorge; a banda Berimbrow convidou Sandra de Sá; Mauricio Tizumba convidou Vagner Tiso. E assim o festival, que durou mais de uma década, seguia em sucesso pleno,tendo sido ampliado para as cidades polo de Minas Gerais, como: Montes Claros, São João Del Rei, Uberlândia, dentre outras.

Mudanças na forma foram acontecendo a cada ano, dentro do próprio festival. O que antes era um festival que apresentava novos talentos aliados a músicos reconhecidos nacionalmente passou a ter etapas eliminatórias, nas quais os vencedores de cada etapa no interior do estado se habilitavam a realizar um show durante o Conexão Telemig Celular em Belo Horizonte. Ocorreram também oficinas de arte-educação em alguns circuitos, como Betim e Uberlândia, e palestras de formação com empreendedores voltados para a música. O Conexão Telemig Celular de Música, em meados dos anos 2000, devido à compra da companhia pela Vivo Celular, mudou seu nome para Conexão Vivo de Música.

Vale lembrar que esse festival trabalhava com artistas via lei de incentivo; aquele artista que havia sido selecionado na lei estadual de incentivo para música agregava seu projeto ao festival. Eram os chamados patrocinados pela Empresa Vivo de Telecomunicação. Havia também aqueles que eram contratados, estes, geralmente, mais reconhecidos no mercado da música e em Belo Horizonte. O festival era considerado pelos artistas como uma das maiores vitrines musicais de Minas Gerais e, passada quase uma década de 
sua criação, o festival se ampliou para cidades como Campinas, em São Paulo; Belém, no Pará; e Salvador, na Bahia.

Nessa etapa de ampliação, a meta era tornar o músico mineiro conhecido no circuito nacional. Foi assim com vários artistas, como o rapper Flavio Renegado e Rodrigo Borges. Ambos convidaram Lenine, respectivamente em Salvador e Belo Horizonte. Celso Moretti, cantor pioneiro do Reggae em Minas Gerais, teve como convidado o baiano Edson Gomes em Belém do Pará e Salvador. Foi uma década de muita evolução no campo do trabalho do músico em Belo Horizonte, na qual o Conexão Vivo teve seu apogeu. Porém, no ano de 2012, a empresa anunciou o fim do Festival.

O músico, compositor e ativista cultural Makely $\mathrm{Ka}$, um dos artistas que esteve presente no festival desde seu início, tanto como artista quanto como curador, reportou-nos, em uma entrevista, uma análise sobre o que foi o Conexão Vivo para o trabalhador da música e o legado para a cidade de Belo Horizonte:

eu pude estar presente em quase todos os festivais e, sim, posso confirmar que foi importante para nosso cenário musical; e também de poder levar a nossa música para outros lugares. Porém, ao passar dos anos, pude perceber que a marca do festival era o que sobressaía. Embora fosse um festival mesclado de novos talentos com os mais consagrados, percebia que era a empresa VIVO quem ganhava mais com o evento. $O$ nome da VIVO meio que cobria a essência do nosso produto; por mais que gravamos CDs e até DVDs, era notável que o festival não conseguia alavancar a carreira dos músicos. De qualquer forma foi interessante todo fomento, mas não consegui ver o Conexão Vivo de música propagar carreiras musicais (MAKELY KA, 2016).

O festival como condição de divulgação da música mineira, se constituiu em um espaço importante de socialização dos novos talentos, assim como as formas de como poderia e deveria ser o trabalho neste importante espaço de trabalho música em Belo Horizonte. Neste festival, também se debatia como seria o próximo ano do festival, se seria aprovado na lei de incentivo ou não. O processo de todo o festival se dava externamente, sob dependência política: só ocorreria o festival via lei, e os músicos se tornaram reféns das leis de incentivo à cultura, assim como o próprio Festival Conexão Vivo.

Para além desse contexto musical na cidade, havia ainda aqueles artistas que despontavam com maior visibilidade, artistas mais jovens, como Pedro Moraes, Rodrigo Borges e Aline Calixto, dentre outros, mas que, ainda hoje, não atingiram seu trabalho em nível nacional como desejado. Um desses artistas, o cantor, compositor e jornalista Rodrigo Borges, que há mais de duas décadas está profissionalmente na música, revelanos a complexidade sobre o trabalho do músico em se colocar no mercado. Ele aponta para a versatilidade profissional que o artista tem que ter, mesmo quando vindo de uma família de músicos. O primeiro fato, no seu caso, é que

Mesmo com o privilégio de ter um maestro em casa, meu pai Marilton Borges [e] meu próprio tio Lô Borges, eu não fui criado para ser músico. A música foi uma opção natural consciente das dificuldades; consciente que é uma missão, porque dentro de casa eu tive basicamente os dois exemplos: os dois de sacrifício, os dois de entrega e luta. Meu pai sempre foi o que a gente chama de operário da música, um cara extremamente criativo, extremamente competente no que ele faz, genial, e que encarou a música como oficio, no sentido de tocar todo dia, de encarar aquilo como profissão, de se preparar, de cumprir horário. Jornadas de trabalho diário no que tange [a] estudos da preparação durante o dia e o labor, né, o trabalho à noite, né. Então eu tive esse exemplo da ralação, né, então a gente não tem amplos direitos: você toca anos numa casa, mas você toca três vezes por semana, isso não caracteriza vinculo. Então, é... a remuneração é mais baixa, [a] maior parte dos músicos agora tem trabalhado para mudar isso, mas não somos tão politizados como o pessoal do 
teatro, por exemplo, nem tão organizados. Então nós temos que nos sujeitar, muitas vezes, a cachê de fome, estruturas precárias de trabalho (RODRIGO BORGES, 2016).

Adotamos aqui o conceito de meio de trabalho, abordado por Ricardo Antunes em "A dialética do trabalho", fazendo um contraponto com a narrativa de Rodrigo Borges, e verificamos uma unidade de pensamento nas descrições deste com o posto pelo autor "um complexo de coisas que o trabalhador coloca entre si mesmo e o objeto de trabalho e que the serve como condutor de sua atividade" (ANTUNES, 2004, p. 38). É preciso entender a profundidade com que cada músico desnuda o significado de trabalho na sua vida, como percebemos nessa primeira parte da entrevista com Rodrigo Borges, aproximar-se do que Ricardo Antunes alude sobre o trabalhador e seu trabalho. Ou seja, a música, para ele, é o "objeto do qual o trabalhador se apodera diretamente abstraindo a coleta de meios prontos de subsistência" (ANTUNES, 2004, p. 38).Essa submissão à precariedade do referido trabalho é um dos poucos meios de sobrevivência que o músico encontra diante do cenário cada vez mais "predatório" no mundo do trabalho.

Aqui, sobre o trabalho do músico, é importante revelarmos a quebra do paradigma segundo o qual a maioria do público pensa que o músico mais se diverte com o que faz do que propriamente exerce um trabalho, um sacrifício em meio às condições colocadas para executar o seu ofício. Rodrigo Borges discorre sobre as "estéticas de mercado" que a grande mídia e as gravadoras impõem, como o sertanejo e o funk, culminando na massificação por um produto basicamente estético cuja intenção principal é a venda. Sobre sua situação nesse cenário com um trabalho musical autoral, ele afirma que

\begin{abstract}
Você hoje tem todo tipo de produção na rede, então fica mais difícil, fica mais difícil você tirar a cabeça "pra fora da água" na rede, né? E fica mais difícil destacar na rede e colocar seu trabalho em evidência. Você tem novas formas de exigência, inclusive de mercado, para você conseguir gerar show. Antigamente era o lbope, que tá perdendo força a cada dia, e isso é ótimo, hoje são as visualizações, e se você não tem um milhão de cliques de acesso você também muitas vezes não existe. $E$ aí a gente volta com as formas mais antigas de disseminação do trabalho que é levar teu trabalho para rua que é o show. Eu acho que, embora eu não esteja na grande mídia, o que mais me deixa feliz, o que mais foi gratificante pra mim nessa última década, é ter consciência que eu tenho trabalhado com a formação de público e uma formação de púbico sólida (RODRIGO BORGES, 2016).
\end{abstract}

Perguntado sobre as políticas culturais voltadas para a música e a própria lei de incentivo, ele diz que

As leis de incentivo foram criadas como reserva de mercado e eu acho que hoje nós temos um desvio de finalidade grande, muitas vezes sobre tudo na Rouanet. As leis de incentivo também viraram critério de negociação e moeda de troca para favores políticos, então na Rouanet é muito difícil artistas de menor expressão conseguirem - não falo nem [de] aprovação, mas acesso ao cofre. Até as grandes empresas já têm politicamente esses instrumentos linkados com a proposta de marketing de influência política que elas necessitam para sobreviverem né. $E$ enquanto reserva de mercado eu acho que são instrumentos importantes, mas nós não podemos ficar dependendo só disso. Eu acho que temos que pensar a cadeia como um todo, tem que pensar no aprimoramento dessas leis de incentivo, tem que pensar numa forma de educação não só do próprio musico, que eu vejo que não tem conhecimento [de] como funciona a lei, de como a empresa vai lidar com isso, conscientizar também as empresas [de] que patrocinar o Rodrigo é legal também. Eu acredito que, no frigir dos ovos, e no fundo disso, tá a educação sempre, né. Pra gente instrumentalizar e operar melhor essas leis de incentivo, a gente precisa de um trabalho de educação forte com a classe artística (RODRIGO BORGES 2016). 
Percebemos que a fala de Rodrigo Borges pontua de forma crítica as relações políticas estabelecidas pelo mercado frente ao trabalho do músico. Importante notarmos que ele expõe a situação atual, porém aponta possíveis caminhos de melhoras para o exercício do seu trabalho e, ao mesmo tempo, é muito convicto sobre sua carreira. Isso nos mostra o quanto é também importante o trabalhador saber sobre sua produção, quais os caminhos possíveis e porque aquele determinado trabalho não conseguiu evoluir dentro deste ou aquele mercado, sobre a política cultural exercida pelo Estado e como os monopólios são construídos. Mesmo que tenhamos, nos últimos tempos, conquistado alguns direitos civis, é preciso que saibamos sobre

\begin{abstract}
Os meios de comunicação, assim como os partidos em seu trabalho de direção política. É importante acentuar, porém, que a atuação da sociedade política é restrita em função da relativa autonomia das instituições da sociedade civil; a estrutura social é dinâmica, as relações sociais são contraditórias e as instituições sociais são permeadas pelo conflito; deste modo, é possível a uma classe inovadora contrapor-se ao formidável "complexo de trincheiras e fortificações" das classes dominantes, há na sociedade civil espaço para emergência da crítica, a elaboração de novas concepções de mundo e a luta por novas relações hegemônicas (GRAMSCl, 2007, p. 31).
\end{abstract}

Estamos tratando aqui da hegemonia cultural que o Estado e os mecanismos de monopólio impõem sobre os vários setores da sociedade em comuns acordos políticos. Através de uma determinada manipulação da arte, a indústria cultural passa a ser o meio para se conduzir e induzir um determinado público a consumir somente aquele nicho cultural de mercado. Assim, as forças de trabalho perdem sua autonomia; no caso do artista, este sempre carregou certa fama de postura contra a alienação comercial, o que o faz ser um trabalhador não alienado. Porém, com os aportes acima, é verificada uma tendência nessas formas de monopólio sobre o produto, o produtor e consumidor, promovendo uma engrenagem dinâmica ao capital. As consequências desses rumos sobre o trabalho do músico não são animadoras, como percebemos na própria situação de desigualdades econômicas para com o trabalhador não músico assalariado e o músico não assalariado. Entre ambas as precarizações, há ainda a mais precária se comparada em relação à outra, que neste caso, é a do trabalhador músico.

O músico, sendo crítico da situação, encontra-se acuado pela imposição do mercado; porém ele também tem em mãos o poder da criatividade e produção intelectual, o que o torna um crítico capaz de elaborar novas formas de sociabilidade com poder de formação de opinião e público. Outro caminho é desenhado pelo artista quando o mundo econômico o oprime, quando the impõe condições de trabalho. Todas essas habilidades do artista versus capital são conhecidas como "os argumentos não monetários da vida de artista" (MENGER, 2005, p. 91).

Entretanto, existe uma fronteira entre a realidade desses argumentos e sua praticidade: "ao mesmo tempo que contribui para o prestígio social das profissões artísticas e para a magia de um tipo de atividade tornado em paradigma do trabalho livre, a incerteza do sucesso gera disparidades... da pirâmide da notoriedade" (MENGER, 2005, p. 91). São os conflitos vividos pelos músicos há séculos, entre o sistema econômico em que ele vive e seu poder de criação. Eis aqui uma grande questão sobre o trabalho do músico:

Como dar conta do projeto de fazer carreira em atividades atraentes mas arriscadas? Logo nas origens da ciência económica, com Adam Smith, uma explicação doravante clássica combinou dois argumentos: por um lado a tomada de risco é incentivada pela esperança de ganhos elevados (enquanto que um cálculo somente baseado na remuneração média obtida no exercício de uma atividade artística seria dissuasivo); por outro lado, um conjunto 
de gratificações não monetárias - gratificações psicológicas e sociais, condições de trabalho atrativas, fraca rotinização das tarefas, etc. (MENGER, 2005, p. 91).

Nessa trilha de pensamento, que mais parece uma eterna condição de quem produz arte, se encontra o mercado de trabalho e suas possibilidades, onde as ofertas estão relativamente determinadas pela procura e os mais beneficiados com o modelo econômico colocado são, consequentemente, favorecidos financeiramente, enquanto alguns dos menos remunerados, que vivem esse dilema há muito tempo, mudam de atividade prioritária para aumento de renda e, mesmo assim, não abandonam totalmente a atividade artística. Esta fica como complemento também de renda e como alimento mental. Mas, geralmente, são poucos os que mudam de atividade laboral, pois entendem a arte como uma missão que deve ser cumprida. Além disso, discursam sobre a racionalização da sua escolha por se manterem fiéis à sua produção artística, fato que, de certa forma, imputa sua condição de marginalizados economicamente, justificada pela disfunção da sociedade moldada pelo domínio de mercado industrial da arte.

Com esse diagnóstico entre a colocação do artista frente à hegemonia do capital sobre sua força de trabalho, temos virtudes de uma autodefesa do músico contra a uniformização da arte e, por conseguinte, seu livramento de uma "condenação" ao fracasso, através da postura em valorizar sua criação, mas principalmente uma luta que Bourdieu (1994, Apud, MENGER, 2005), em "Le marche des biens symboliques", chama de defesa contra o desencanto. É importante sabermos que toda a história das artes traz consigo o drama, o lamento, a dor, a alegria dessa conquista, as genialidades, e que todo esse conjunto se torna consolador diante das metamorfoses econômicas do capital.

Analisando os caminhos que as obras de arte tomam na história da humanidade, verificamos que, embora dificilmente seja determinante para mudar o curso da história daquela ou desta sociedade, é perceptível que a arte contribui para o legado de um povo. Estamos debatendo aqui as rupturas econômicas entre mercado de trabalho do artista, monopólio político nas formas de divulgação das obras desses artistas e resistência do artista frente ao capital. É preciso, contudo, buscar um aprofundamento nos modelos de produção, na reprodução dessas obras de arte, em nosso caso, a música, para que possamos dar uma ordem cronológica e absorver as mudanças em que a obra de arte está submetida, porque

\begin{abstract}
Em sua essência, a obra de arte sempre foi reprodutível. O que os homens faziam sempre podia ser imitado por outros homens, essa imitação era praticada por discípulos, em seus exercícios, pelos mestres, para a difusão das obras, e finalmente por terceiros, interessados no lucro. Em contraste, a reprodução técnica da obra de arte representa um processo novo, que se vem desenvolvendo na história intermitentemente, através de saltos superados por longos intervalos, mas com intensidade crescente (BENJAMIN, 2012, p. 180).
\end{abstract}

Essa cronologia sobre a obra de arte e sua reprodutibilidade se assemelha às transições de modelos econômicos que a história nos permite visitar. Ainda que a arte não floresça de comum acordo com os processos econômicos das sociedades em determinadas épocas, ela está sempre presente como protagonista das provocações sociais. Isso é importante destacar aqui, porque quando analisamos o discurso dos músicos, é notório que muitos atribuem a precarização do seu trabalho ao tempo atual, à reprodutibilidade tecnológica, naquele velho exemplo da substituição do músico de bar por um sistema de som mecânico ou jukebox. Entretanto, no fundo desse debate, estão as formas como a própria sociedade enxerga aquela determinada obra de arte. 
Reconhecemos que os processos mercantis da indústria cultural, desde a segunda guerra mundial, se reformulam e se adaptam a todo momento; sim, isto é fato, mas cabe ao trabalhador músico, além de promover inquietações, junto com sua obra de arte, também conseguir transpô-las para o plano político prático. Podemos afirmar aqui, embora estejamos vivendo todos os processos de exclusão pelo mundo, que o artista é aquele com mais condição de propor inovações e provocações com suas ideias criativas. É nesse cenário que se conforta o lugar do músico: ainda que esteja diante de toda uma precarização nas condições de trabalho, é ele como trabalhador que pode promover novidades sociais e sonoras.

\section{A nova ordem musical na CIDAde de Belo HoRIzonte}

As questões da nova ordem musical de Belo Horizonte, com dados de seu processo histórico, foram articuladas com as referências da prática atual do órgão que se ocupa do ordenamento da cultura na cidade - a Belotur. A entrevista com o poeta e folclorista Tadeu Martins foi importante para realizarmos essa análise.

Assim ao reportarmos à historiografia, vimos que a cidade de Belo Horizonte, antes mesmo de ser construída para ser a capital de Minas Gerais, já fazia sua música. Construída onde era o povoado chamado de "Arraial do Curral Del Rei", com a chegada dos operários para sua construção, a cidade abrigou entre os trabalhadores muitos músicos, que, nas horas vagas, sempre faziam seus festejos regados a muita música, cachaça e torresmo.

Na pesquisa, conseguimos verificar inúmeras fontes dos conflitos políticos da época em Ouro Preto, dos prós e contras da transferência da capital de Ouro Preto para o Arraial do Curral Del Rei. O momento dessa transferência coincide com o período da proclamação da república, e os ideais da elite burguesa e política da época estavam em jogo. Segundo Julião, "A nova Capital parecia se erguer sobre os escombros da antiga ordem; abandonava-se à própria sorte Ouro Preto e arrasava-se o Curral Del Rei, deixando poucos vestígios para a posteridade" (JULIÃO, 2011, p. 126). O que imperava no momento dessa construção era que nascia ali um novo símbolo de modernidade no Brasil e o progresso enfim chegava a Minas Gerais.No ano de 1891, a Constituição Mineira assegurou a transferência da capital e, em 1893, foi decidido o local.

E a música caminhava junto com a cidade. Ela foi muito importante para sua construção porque, antes mesmo da efervescência da construção da cidade, já havia uma orquestra formada por operários, que chegavam dos vários lugares de Minas, Brasil e Europa. Era a orquestra Carlos Gomes, mais velha do que a própria cidade. Além da orquestra, havia vários outros músicos que já faziam suas apresentações pelas praças em construção e cabarés que se inauguravam com a chegada de tantos trabalhadores e novos moradores. Assim, toda essa musicalidade e as referências dos arredores, como Sabará, Ouro Preto e Mariana, contribuem para o nascimento do carnaval antes mesmo da cidade, como conta Tadeu Martins.

A capital é oficializada e inaugurada dia 12 de dezembro de 1897, no carnaval deste ano, ou seja, dez meses antes da inauguração da cidade os construtores fizeram o primeiro carnaval. O que é que tinha? Carroças enfeitadas, assim os músicos da época iam em cima das carroças, muito sopro, muita percussão, e começou da Praça Sete, passando pela Avenida João Pinheiro. Depois desciam para o Parque Municipal. Ali, após o cortejo, acontecia o baile. Então, primeiro começou com as carroças fantasiadas, [a] isso deu-se o nome depois de corso; segundo, muita gente fantasiada em cima das carroças com as caras 
pintadas, se tornou os blocos caricatos; terceiro o povo pulando atrás da música que vinha dessas carroças, bandas ou blocos; e, quarto, a parada no Parque Municipal que se tornou o baile. Assim foram os quatros pilares do carnaval de Belo Horizonte e as escolas de samba só vieram após a primeira guerra mundial, e a cidade não tem tradição de escolas de samba (TADEU MARTINS, 2017).

Nesse contexto, automaticamente durante o burburinho da inauguração da cidade, o povo tomou a Praça da Liberdade, fazendo o que os mais velhos chamaram de segundo carnaval no mesmo ano. A diversidade étnica, com predominância negra, já provocava a cidade antes mesmo de ela nascer e a música era o instrumento de apresentação. Os festejos sagrados e profanos migravam das cidades coloniais juntamente com os operários para a capital; por isso, temos tantos Reis e Rainhas Negras Congas pelas periferias de Belo Horizonte e alguns terreiros de candomblé com mais idade que a cidade.

Assim "sempre houve carnaval agora tudo é carnaval" é uma provocação, devido à necessidade de apresentar uma cidade cuja história parece estar no subterrâneo, o que gera a impressão de que por aqui tudo começou agora, porque a cidade é uma das capitais mais novas do Brasil. A provocação é justamente para fazermos um contraponto com o renascimento do carnaval de Belo Horizonte no ano de 2008, em que vários coletivos de artistas, indignados com os rumos políticos que a cidade vinha tomando, os retrocessos por via do poder municipal, como já discorremos neste artigo, levaram uma juventude indignada a romper padrões conservadores - que muitos chamam, ironicamente, de "a família tradicional mineira".

Ao mesmo tempo, nas periferias de Belo Horizonte, o carnaval nunca deixou de existir, e a prefeitura municipal também patrocinava os bailes regionais. Em alguns anos, a prefeitura ousava, colocando os desfiles dos blocos caricatos na avenida principal da cidade, a Afonso Pena; em outros anos, transferia para outros locais, como a Via 240, no bairro Tupi, na região nordeste da cidade. Entretanto, sempre havia críticas da população, que reclamava que a cidade não tinha carnaval e que só ficava em Belo Horizonte o povão que não tinha condições de viajar para outros lugares. Assim, faziam do carnaval um verdadeiro atestado de pobreza, o que, na verdade, não era.

O que se via era o povo negro mesmo, que ali festejavam de maneira ancestral sua cultura, e a cidade de Belo Horizonte, dividida pela cor, nunca deu conta de aceitar que mais de sua metade é totalmente negra. Então, o carnaval da cidade, por muito tempo, ficou representado pelo povo que a construiu. Desde de seu nascimento, esse povo negro sempre foi um incômodo para a elite política e econômica da cidade, cujo projeto incluía a vinda de imigrantes europeus para o "embranquecimento" do Brasil. Belo Horizonte seria a cidade modelo, inclusive nisso, tanto que a arquitetura também partiu das referências modernistas europeias da época.

O carnaval, que, nos últimos anos, vem atraindo milhares de pessoas para a capital, iniciou-se com os blocos Tico Tico Serra Copo, Chama o Síndico, Então Brilha!, Baianas Ozadas, Pavão de Pena Krishna e Alcova Libertina, dentre outros, cujos repertórios são os mais diversos possíveis, de Tim Maia a Jorge Ben Jor, do Axé music ao Rock dos Stones; tem para todos os gostos. Isso faz do carnaval de Belo Horizonte um diferencial das demais cidades grandes que sediam a folia: por aqui os blocos, em sua maioria, saem durante o dia. Essa foi uma característica inovadora dos coletivos de artistas envolvidos nesse novo momento carnavalesco, que já caminha para uma década de retomada na cidade. 
Dados da pesquisa realizada pela Secretaria de Estado de Turismo e Esportes em Minas Gerais e a Belotur apresentam números interessantes sobre o fenômeno da retomada do carnaval em Belo Horizonte. Ela aponta que

O carnaval de Belo Horizonte de 2016 gerou uma renda de $R \$ 54,7$ milhões para o município, $233,5 \%$ a mais do que a folia de 2015 , que gerou $R \$ 16,4$ milhões. O número de visitantes no evento também aumentou 124,1\%, de 42.905, em 2015, para 96.144, em 2016. Os dados são de uma pesquisa feita pela Secretaria de Estado de Turismo e Esportes de Minas Gerais em parceria com a Empresa Municipal de Turismo de Belo Horizonte (Belotur), divulgada nesta terça-feira. O gasto médio diário dos visitantes também aumentou. Passou de $R \$ 99,42$, em 2015 , para $R \$ 157,61$, em 2016 , ou seja, 58,5\% a mais. O fluxo estimado de pessoas, segundo dados da Polícia Militar, passou de 1,458 milhão para 2 milhões (FERREIRA, 2016).

Contudo, referida pesquisa não aborda o trabalho dos músicos e demais artistas envolvidos para colocarem o bloco na rua. $O$ que se sabe é esses fazem vaquinhas eletrônicas quando não atingem as metas e, em alguns blocos, os integrantes tiram dinheiro do próprio bolso para realizar o desfile. A prefeitura, até aqui, não foi eficiente para com os blocos; somente a partir de 2018 é que lançou um edital financeiro para o carnaval, o que também não resolve totalmente o volume de custo para fazer os blocos colocarem centenas de milhares de pessoas pelas ruas de Belo Horizonte, como fazem os blocos citados acima. Ainda que a nova gestão municipal traga alguns benefícios para os coletivos responsáveis por fazerem acontecer o carnaval de Belo Horizonte, não é este o desejo dos ativistas culturais, visto que contraditoriamente são retirados boa parte dos nossos direitos. O processo desejado pelas bases desse levante cultural é o diálogo considerado "horizontal" em que todos têm voz e no qual todos colhem, juntos, os frutos.

Foi assim desde o início desse novo momento social vivido na cidade: as reuniões nas ocupações por moradia popular, por toda a região metropolitana; os espetáculos e os shows de artistas que, além de doarem o cachê em prol das várias causas sociais, doam também um bom tempo das suas vidas promovendo ações políticas de conscientização coletiva nas universidades públicas de Belo Horizonte e demais espaços públicos da cidade. O poder coletivo, considerado poder para o povo, foi aos poucos tomando forma, e o Carnaval da cidade de Belo Horizonte é hoje uma realidade de que o poder público desdenhou abrindo mão do diálogo com o povo. Isso significa que

\begin{abstract}
Nas sociedades contemporâneas, permeadas por uma mudança acelerada e expostas ao risco da catástrofe, torna-se mais evidente que os processos sociais são produtos de ações, de escolhas, de decisões. O agir coletivo não é o resultado de forças naturais ou de leis necessárias da história, nem, de outro lado, simplesmente o produto de crenças e de representações dos atores. De uma parte, a tradição tem radicado os conflitos na estrutura social, em particular, na estrutura econômica, e os tem explicado como uma espécie de necessidade histórica (MELUCCI, 2001, p. 31).
\end{abstract}

Dentro dessa necessidade histórica, é preciso dá voz aos sujeitos protagonistas, os que se levantam, que ocupam lugares que, até uma década atrás, estavam totalmente fechados para o diálogo com o saber social vindo de quem faz a arte na cidade. Ouviamse gritos que ecoavam e passavam despercebidos juntos ao vento leste, vozes que buscavam simplesmente um lugar, um direito à cidade, um direito de festejar, celebrar, cantar a vida. Como diria o revolucionário músico brasileiro Francisco de Assis França Caldas Brandão, mais conhecido pela alcunha de Chico Science: "o homem coletivo sente a necessidade de lutar". O movimento denominado "mangue", ocorrido na cidade de Recife no início dos anos 1990, teve seus ecos pelo Brasil todo em prol da valorização 
da cultura local, mais precisamente a música autoral, que sempre sofreu a imposição da grande indústria cultural em uniformizar e determinar o que o povo deve consumir como arte, mais precisamente a música.

Em Belo Horizonte, os ecos do movimento "mangue" foram ouvidos e representados paralelamente pelos principais ativistas da música mineira. Ao seu modo, a juventude de Belo Horizonte assimilou tudo isso e criou suas novas formas de sociabilidade através da música. Tomou para si o poder da liberdade coletiva para criar seus próprios festivais de música, com uma estética que representa uma diversidade cultural da cidade. Era como dizer "todo mundo é artista, eu também sou", frase da vinheta do programa de sábado à tarde na Rádio Inconfidência denominado "Favela é isso aí", realizado pela ONG de mesmo nome.Seguimos lutando e acreditando na Arte. A Ciência tem a oportunidade de poder usar Arte como instrumento e a Arte, em algumas situações, usa também a Ciência. Assim como a própria vida imita a Arte, é chegado o momento de vermos a Arte nos seus variados ângulos, não só sob viés do entretenimento ou do lúdico.

\section{REFERÊNCIAS}

ADORNO, T. W. et al. Teoria da cultura de massa. São Paulo: Paz e Terra, 2000.

ADORNO, T. W.; HORKHEIMER, M. Dialética do esclarecimento: fragmentos filosóficos. Rio de Janeiro: Jorge Zahar, 1985.

ANTUNES, R. A dialética do trabalho: escritos de Marx e Engels. São Paulo: Expressão Popular, 2004.

BENJAMIM, Walter. Magia e técnica, arte e política: ensaios sobre literatura e história da cultura. Editora Brasiliense Ltda. São Paulo 2012. p. 180

BOSI, E. O tempo vivo da memória: ensaios de psicologia social. São Paulo: Ateliê Editorial, 2003.

CUNHA, D. M. Aspectos da estrutura e do funcionamento da atividade humana em Aléxis Leontiev. In: ARANHA, A.; CUNHA, D.; LAUDARES, J (Orgs.). Diálogos sobre o trabalho: perspectivas multidisciplinares. Campinas: Papirus, 2005.

ELIAS, Norbert. A sociologia de Mozart. Belo Horizonte: Autêntica, 2007.

FREIRE, Paulo. Educação e mudança. Rio de Janeiro: Paz e Terra, 2007.

FERREIRA, Pedro. Disponível em:

https://www.em.com.br/app/noticia/gerais/2016/03/01/interna_gerais,739131/carnaval-2016-gerou-rendade-r-54-7-milhoes-para-bh-e-publico-aumento.shtml. Acesso em: 03 set. 2019.

FUNDAÇÃO JOÃO PINHEIRO. Centro de Estudos de Políticas Públicas. Diagnóstico da cadeia produtiva da economia da música em Belo Horizonte. Belo Horizonte: FJP, 2010.185p.

GRAMSCI, A. Hegemonia e cultura. Curitiba: UFPR, 2007.

JULIÃO, L. Sensibilidades e representações urbanas na transferência da Capital de Minas Gerais. História, São Paulo, v. 30, n. 1, p. 114-147, jan.jun. 2011. Disponível em: $<$ http://www.scielo.br/pdf/his/v30n1/v30n1a06.pdf>. Acesso em: 03 ago. 2017.

LEÃO, Andréa Borges. Nobert Elias \& a educação. Belo Horizonte; Autêntica, 2007.

MAUAD, A. M. Fontes de memória e o conceito de escrita videográfica: o propósito dafatura do texto videográfico Milton Guran em três tempos. Oralidades: Revista deHistória Oral, São Paulo, v. 13, n 1, p. 141-151, jan-jun. 2010.

MARX, K.; ENGELS, F. Sobre Literatura e arte. São Paulo: Global,1986.

MARTINS, L. M. A orilatura da memória. In: FONSECA, M. N. S. (Org). Brasil afro-brasileiro. Belo Horizonte: Autêntica, 2006. 
MENGER, P.-M. Retrato do artista enquanto trabalhador: metamorfose do capitalismo. Lisboa: Editora Roma, 2005.

MELLUCI, Albert. A invenção do presente. Petrópolis: Vozes, 2001.

NORA, P. Entre Memória e História: a problemática dos lugares. In: Projeto História. São Paulo: PUC, n. 10, pp. 07-28, dezembro de 1993.

Data da submissão: 08/03/2019

Data da aprovação: 03/08/2019 